\title{
Sensibility and Rationality in Vocal Music: The Issue of Intonation
}

\section{Sensibilidade e racionalidade na música vocal: a questão da entonação}

\author{
(iD) Di Wang 1 \\ Art Academy, Hubei Polytechnic University, Huang Shi, China \\ diwang422@yahoo.com,wangdi352677230@sina.com
}

\begin{abstract}
The purpose of this article was to assess the effectiveness of intonation control among first-year students majoring in vocal music. The study was performed during the 2018-2019 in on one of Beijing conservatories (China). Research sample comprised of 300 first-year students, 100 of which made up the control group, another 100 - the experimental group 1, and the last 100 - experimental group 2. Higher results of students from EGs than those of CG participants resulted from systematic and constant work on intonation improvement. The total number of individuals with poor educational achievements decreased in view of the innovative training methodology introduction that provoked the overall enhancement of academic outcomes. An inverse correlation was found between intonation control and health vocal apparatus: -0.89 for CG, 0.78 for EG1, and 0.81 for EG2. The application of the developed methodology allowed students to preserve vocal cords' health and improve singing abilities.
\end{abstract}

Keywords: control; experiment; intonation control; singing; vocal apparatus.

Resumo: O objetivo deste artigo foi avaliar a eficácia do controle da entonação entre os alunos do primeiro ano com especialização em

1 Di Wang has a Master degree. Currently a teacher at Art Academy, Hubei Polytechnic University, Huang Shi, China. Research interests are vocal music, intonation, intonation control, self-control practices, and skills development 
música vocal. O estudo foi realizado durante o período de 2018-2019 em um dos conservatórios de Pequim (China). A amostra da pesquisa foi composta por 300 alunos do primeiro ano, dos quais 100 constituíram o grupo controle, outros 100 - o grupo experimental 1 e os últimos 100 - o grupo experimental 2. Resultados superiores dos alunos dos GEs do que dos participantes do GC resultaram da sistemática e trabalho constante na melhoria da entonação. O número total de indivíduos com baixo desempenho educacional diminuiu em vista da introdução de metodologia de treinamento inovadora que provocou a melhoria geral dos resultados acadêmicos. Foi encontrada correlação inversa entre o controle da entonação e o aparato vocal saudável: -0,89 para o GC, 0,78 para o GE1 e 0,81 para o GE2. A aplicação da metodologia desenvolvida permitiu aos alunos preservar a saúde das cordas vocais e melhorar as habilidades de canto.

Palavras-chave: ao controle; experimentar; controle de entonação; cantoria; aparelho vocal.

Submetido em: 30 de outubro de 2020

Aceito em: 17 de março de 2021 
Sensibility and Rationality in Vocal Music: The Issue of Intonation Di Wang

\section{Introduction}

In the modern sense, the concept of individuality combines the desire to embody one's inherent skills and abilities and develop personal identity. The life credo of a present-day personality includes such elements as dynamic skills development, mastering new abilities, socialization, and his/her inclusion in the globalization process (D'AMARIO et al., 2020). To ensure a well-controlled development of all these elements, one should be able to forecast and perform his/her professional activities in a conscious and deliberate way, for example, through the implementation of selfcontrol practices. Though, it should be noted that among many modern students, and often even teachers of various disciplines (including music ones), no precise understanding of how they can realize their abilities through self-control exists (ZHANG et al., 2020). Today, a fundamentally erroneous idea of self-control as a negative factor of influence on creativity is actively developing in singers' circles (ZAPOROWSKI and CZYŻEWSKI, 2019; ZAPOROWSKI and KOSTEK, 2020).

Nevertheless, self-control, as the main element of a rational approach to creative skills development, takes a rightful place in most educational programs of the world's leading music universities. Rationality does not always lead to the expected results (HAVRØY, 2013). However, in the case of systematic actions focused on singing abilities development, students can get a clearly better result compared to the traditional training methodology, which does not include rationality as a compulsory component. The available literature in this field lacks works that consider specifically the results of the rational approach application by singing students. At the same time, the existing indicate that when rationalizing one's singing, it is necessary to develop sensitive (intonational) control (DEVANEY et al., 2011). In the case of vocal music, sensibility directly refers to intonation (HOWARD, 2007). Though, if referring to any other field, related not to singing, but other types of creativity, it would be better to call this approach 
Sensibility and Rationality in Vocal Music: The Issue of Intonation Di Wang

sensitive, since control is carried out over one's sensitive sphere of activity and reality perception (DAFFERN, 2017; HAVRØY, 2015; GINSBORG and KING, 2012).

Russian researchers indicate that about half of the respondents enrolled in studies on singing have problems with voice and speech (GONTARENKO, 2007). In the meantime, about one-third of such problems are related to the anatomical structure of the vocal apparatus. According to the Russian Public Voice Academy, such voice disorders are associated not only with a factor of adverse environmental impact but also with improper singing or declamation techniques (GONTARENKO, 2007). They can result from a wrong intonation since, during singing, inexperienced performers may use incorrect techniques of voice production, leading to disturbances in the structure and functioning of the vocal apparatus (D'AMARIO et al., 2018). Thus, controlling intonation can be a decisive factor in preserving a singer's health and in the correct development of his/her creative abilities (D'AMARIO and DAFFERN, 2017; D'AMARIO et al., 2019, 2020).

In Asian countries, the art of singing has its own specific features. In particular, notation there is not assigned a leading role since it is believed to distract the student from real merging with the creative activity. Furthermore, Asian performers pay attention not to the means of teaching but rather to the singing itself as it is believed that the mastery is transmitted from the teacher to the student only in the process (SCHERER et al., 2015). In China, the presence of an experienced instructor is deemed necessary to achieve an excellent performance of any musical piece. Even though Chinese musicians and singers had a notation system already two millennia ago, improvisation was necessary to fully comprehend a piece of music and merge with a melody. Japanese singing students usually imitate the teacher in his/her singing (use the technique of solmization) or sing mnemonic syllables. The Indian tradition of singing (sargam) also uses the technique of solmization. The Iranian tradition is characterized by similarity to the techniques used in India. Solmization is also practiced in jazz 
Sensibility and Rationality in Vocal Music: The Issue of Intonation Di Wang

since there is an opinion that in this way a musician can improve the sense of rhythm. Meanwhile, traditional music education in the Eastern world aims not to 'accelerate' learning, but provide students with natural and gradual comprehension of music 'from the inside' (DELIĆ et al., 2019; KERKENI et al., 2019; MUNIR et al., 2019; SEZGIN et al., 2012; ZHAO et al., 2019).

For a better understanding of the singing process, it is necessary to mention briefly the functions of the main organs involved (HOWARD and ANGUS, 2017; KUMAR and SHIMI, 2015). Breathing has a top role in the singing process as it provides proper sound quality and volume level. A student can achieve an ideal breathing cycle by the most accurate repetition of the teacher's inhalation and exhalation sequences. By doing this, a singer can develop a sense of control over voice power. Greater mastery will allow exploring a broader range of notes. Appropriate breathing exercises make it possible to realize the movement of one's own muscles and its connection with the strength of the sound produced. The most difficult for singers are believed to be exercises directed at the improvement of larynx control while singing (MARKOFF, 2019). To become a good singer, one also needs to understand the anatomical structure of the larynx and know that it is formed of cartilages that are held together by ligaments and membranes, moved by muscles, and lined by mucous membrane. In addition, one should be aware of the opportunity to stimulate the movement of the entire larynx and its individual cartilages. These points are deemed important as their knowledge provides extensive opportunities for improvisation while singing (BERTERO and FUNG, 2017).

The issue under consideration is exceptionally relevant since there are no studies specifically focusing on intonation (related to the sphere of sensibility) and a rational approach to singing. This fact determined the relevance of this research.

The present work is at the crossroads of several disciplines. Together with to the main topic directly related to music (namely, singing), this research also touches on the acoustic issues since 
Sensibility and Rationality in Vocal Music: The Issue of Intonation Di Wang

it investigates the influence of the correct approach to intonation and changes in the creative potential of singers enrolled as respondents. The study findings can be applied in medicine, since proper intonation training will reduce the load on the vocal apparatus and, thus, contribute to the full-fledged work of a singer. The authors assume that the application of specially developed training methodology will enhance respondents' singing and creative skills. In order to test this theory, the present work is divided into two parts. The first is aimed at discussing the results of a medical examination of respondents' vocal apparatuses. The second, in parallel, presents the outcomes of applying an innovative approach to improving the sensibility (intonation) of singing and reviews its impact on students' performance.

The purpose of this study was to 'battle-test' the intonational abilities of students majoring in vocal music, regarding this as a necessary requirement for their singing potential realization. The research objectives included the assessment of the singing potential in control and experimental groups before and after the experiment, and comparing the results obtained among men and women.

\section{Materials and methods}

\section{Materials}

The study was carried out in 2018-2019, based on one of the conservatories in Beijing (China). Research sample included 300 first-year students of the Vocal Music Department, 100 of which made up the control group, another 100 - the experimental group 1 , and the last 100 - experimental group 2 (these were distance students). For identity in the subsequent comparison, each group had an equal number of male and female individuals (50). The groups' age composition is given in Table 1 . 
Sensibility and Rationality in Vocal Music: The Issue of Intonation Di Wang

Table 1 - Respondents' average age by groups.

\begin{tabular}{c|c|c}
\hline Group & Average age of males & Average age of females \\
\hline Control & $17.1 \pm 0.3$ & $17.4 \pm 0.2$ \\
\hline Experimental 1 & $17.2 \pm 0.2$ & $17.2 \pm 0.4$ \\
\hline Experimental 2 & $17.5 \pm 0.1$ & $17.2 \pm 0.2$ \\
\hline
\end{tabular}

There were no significant differences in age within the groups and between them.

\section{Research design}

The control group (CG) included full-time students underdoing a standard course of vocal music practice. Experimental group 1 (EG1) also consisted of individuals studying full-time, but they were additionally engaged in the specially developed training methodology proposed by the authors. These two groups' classes were held in one room. That is, the teacher worked with them together but using different methods, which is in line with the principle of mass education adopted in Western countries. Experimental group 2 (EG2) consisted of students who were undergoing an individual study and visited the educational institution only for passing exams. As EG2 participants were also involved in the experimental training, they passed the course program with teachers face to face. The name of the educational institution and respondents' personal data were not disclosed to maintain the principles of confidentiality and anonymity. A writing agreement guaranteeing anonymousness and non-disclosure of any personal information was concluded with each of the students enrolled. Given this, the present study observed all moral and ethical standards generally accepted in world practice.

\section{Research methodology}

The duration of each lesson in every group did not exceed 25 minutes with breaks in order not to harm students' vocal cords. 
Sensibility and Rationality in Vocal Music: The Issue of Intonation Di Wang

In the second half of the academic year, the lessons' duration increased to the standard 45 minutes as vocal cords' strength increased after regular training. Besides, to ensure the health of respondents' vocal apparatuses, a preventive examination of all research participants was carried out every half-year. In this regard, already in the second half of the academic year, 16 people were excluded from CG as the state of their vocal cords was not considered satisfactory.

CG participants studied according to the standard first-year program, which included singing lessons, mastering the basics of musical theory, and participation in small-scale pilot performances in solo and choral singing modes. No intonation correction was performed for them. Students from both EGs were supervised by teachers and were allowed to propose teaching methods and techniques that, in their opinion, could improve their educational process and correct some of its negative aspects. During the first half of the academic year, students from EG1 and EG2 received the opportunity to listen to music, both in recording mode and performed live by teachers. Besides, they were engaged in classes in the professional opera studio and took part in opera performances. This decision was provoked by the assumption that understanding the relationship between dramaturgic content and context, on the one hand, and vocal intonation, on the other, will positively influence the formation of one's self-control over intonation. An additional factor that supposed to intensify the positive outcomes of the proposed training methodology was the possibility to participate in the opera performance through solo singing, as well as through full interaction with the rest of the vocal ensemble members. In such a way, young singers could achieve full-fledged artistic communication, comprehend the meaning of the intoned word and notice changes in the sense of the artistic image in the sounding piece. It was assumed that a full-fledged students' participation would enable them to control intonation better while singing. 
Sensibility and Rationality in Vocal Music: The Issue of Intonation Di Wang

The concept of intonational self-control is rooted in the field of acoustics theory and physiology since it is largely due to the socalled muscle memory. By this is meant the kinesthetic sensitivity, manifested in the form of muscle actions that appear when we produce sounds. At the initial stage of training, the work of the vocal apparatus of a beginning singer is subordinated to the sense of hearing. Only after that, skill development occurs. Consequently, it can be assumed that more experienced students control singing intonation by their muscle memory rather than the sense of hearing. In order to ensure the full realization of the artistic image, students from EGs were recommended to connect with vocal intonation their other feelings, which, at first glance, were not related to the singing process. These included, first of all, visual images of a sound, which, in addition to the auditory perception of intonation, can give it unique emotional coloring. Despite its queerness, such a connection of senses enabled the assessment of voice tone and pitch. In addition, students had the opportunity to see the intonation dynamics by associating it with one's own artistic images.

Students' work was evaluated every half-year by comparing their learning outcomes. Accordingly, three levels of academic performance were identified: high, average, and low. In the context of educational achievement, comparisons were made between the results of all the groups involved and between males and females within each group. Moreover, the CG, EG1, and EG2 were compared in terms of the number of dropouts for health reasons (problems with vocal cords detected during medical examinations).

\section{Statistical analysis}

The obtained data (student ratings) were statistically processed using the capabilities of the Statistica v. 6.0 (StatSoft Inc., USA). This software was also used when calculating arithmetic mean and standard error of the mean. The study applied nonparametric 
Sensibility and Rationality in Vocal Music: The Issue of Intonation Di Wang

methods of statistical analysis and used the Mann-Whitney $\mathrm{U}$ test to evaluate differences between groups (significant at the level of $p \leq 0.05)$.

\section{Results}

\section{Dynamics of voice disorders among respondents}

During the research process, significant differences in the number of students dropping out because of voice problems were noted only between control and experimental groups (Figure 1).

Figure 1 - Number of dropouts due to voice problems.

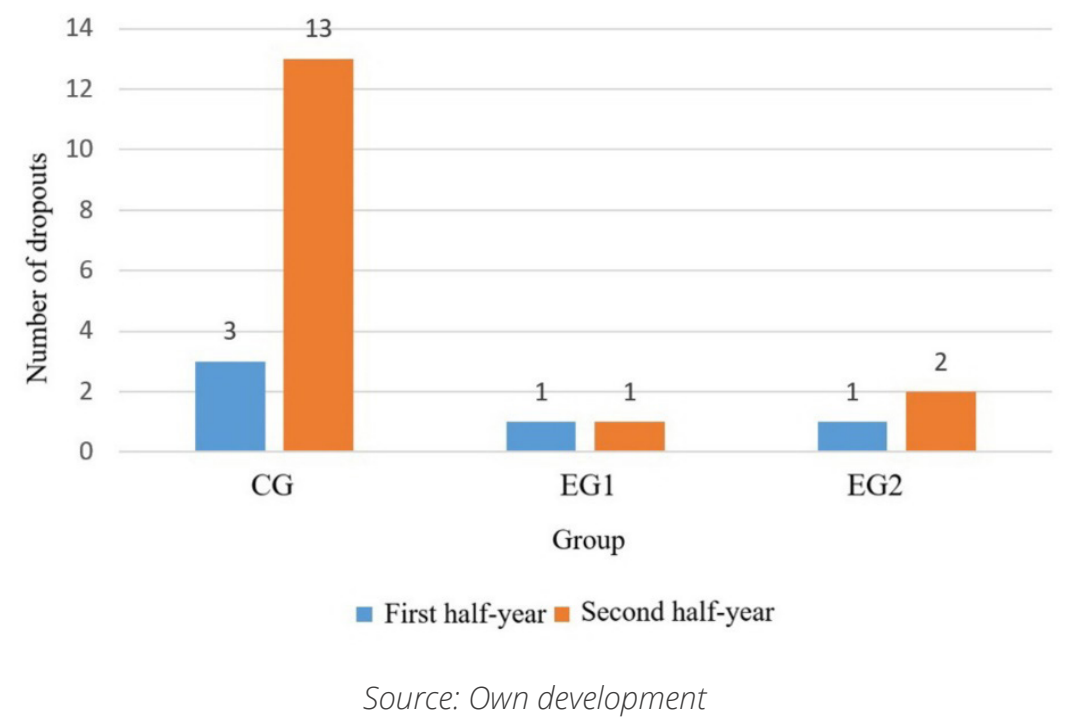

The number of participants dropped out from CG already in the first half of the academic year was three times higher than those in EG1 and EG2 ( $p \leq 0.05)$. In the second half-year, this gap increased. The number of CG dropouts was 13 times higher than that in EG1 ( $p \leq 0.001)$, and 7.5 times higher than in EG2 ( $p \leq 0.001)$. Given this, one can assert that CG respondents' health deteriorated much faster with a tendency to accelerate in the second half of the academic year. According to the medical examination results, two 
Sensibility and Rationality in Vocal Music: The Issue of Intonation Di Wang

main reasons for this were revealed. The first was various voice disorders, and the second - vocal cords' damage (Figure 2).

Figure 2 - Number of CG dropouts depending on the type of voice problems

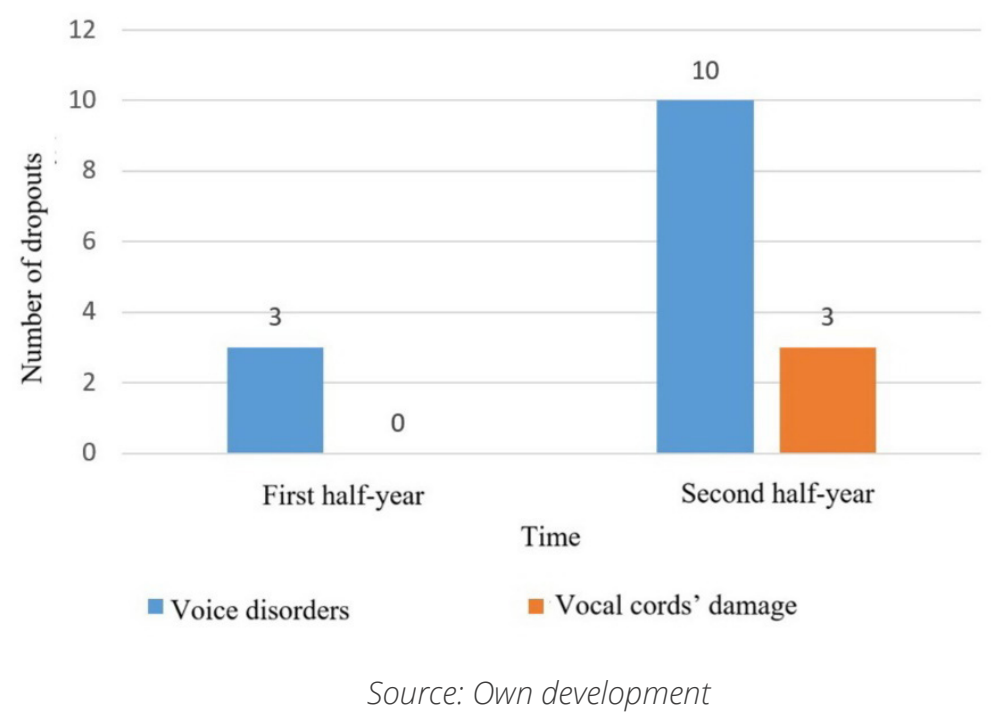

In the first half of the training year, the number of CG students who dropped out due to voice and speech disorders was 3.3 times less than in the second half-year $(p \leq 0.05)$. Concurrently, in the first half-year, students with damaged vocal cords were not noted at all, whereas in the second, such a group of individuals was already present. Nevertheless, voice and speech disorders took place 3.3 times more often than cases of the vocal cords' damage ( $p \leq 0.05)$.

These data imply that increasingly more CG students suffered from voice and speech disorders and injured their vocal cords in the process of learning. Therefore, while applying traditional teaching methodology, it is necessary to monitor the health of students closely.

\section{Intonation control influence on students' performance}

It was found that the number of male CG students with low academic performance exceeded that of EG1 and EG2 by 1.2 times 
Sensibility and Rationality in Vocal Music: The Issue of Intonation Di Wang

already at the end of the first half-year ( $p \leq 0.05$, Figure 3 ). At the same time, the investigation revealed no significant differences between the number of students with an average level of academic success for all three groups. As for the high educational attainment, 1.3 times more male students from EG1 and EG2 had a high rating at the end of the first half of the academic year compared to their CG fellows $(p \leq 0.05)$. In the second half-year, the number of CG students with poor performance decreased by 1.3 times ( $p \leq$ 0.05) compared to the first one. More drastic changes occurred among respondents from the EGs. The number of those with a low performance level decreased by 4.3 times in EG1 $(p \leq 0.01)$ and by 9.1 in EG2 ( 1 0.001). Besides, it was notable that the number of study participants with moderate educational achievements increased more sharply in EG1 and EG2 than in CG in the second half of the year compared to the first - by 2 and 1.5 times, respectively $(p \leq 0.05)$. The high level of academic achievement in the second half-year also showed positive dynamics -1.2 times for $C G$ and 1.5 times for EGs $(p \leq 0.05)$.

\section{Figure 3 - Changes in performance of male respondents}

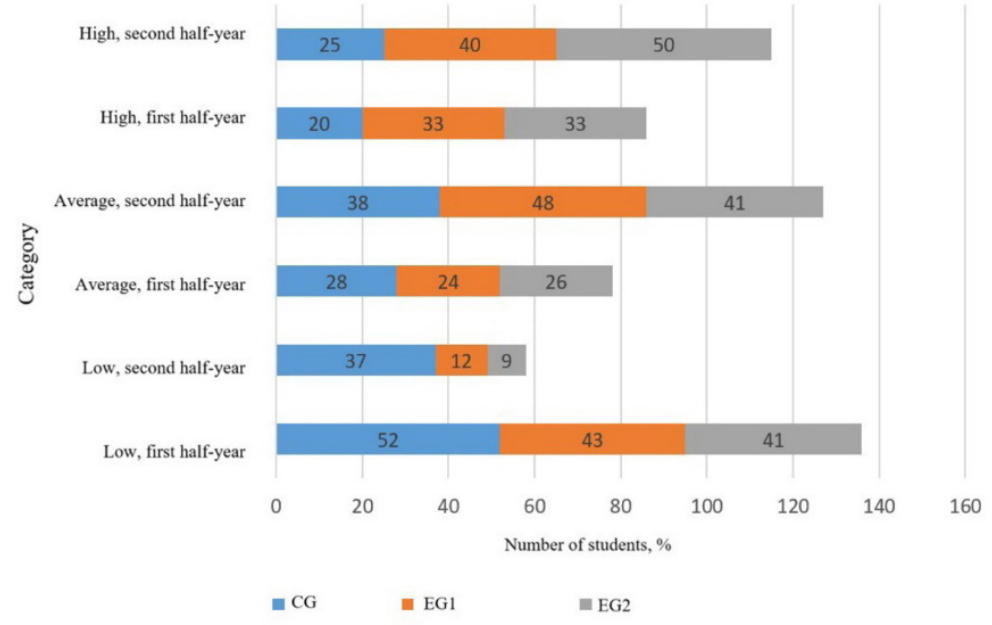

Source: Own development

For females, similar results were registered (Figure 4). Hence, during the first half-year, the number of female students with a 
Sensibility and Rationality in Vocal Music: The Issue of Intonation Di Wang

low rating in $E G 1$ and $E G 2$ was 1.3 times less than in $C G(p \leq 0.05)$. No significant differences were recorded for the average academic performance level, while the number of female singing students with excellent educational outcomes in EG1 and EG2 was 1.3 times higher compared to CG $(p \leq 0.05)$. In the second half of the year, the gap increased. The number of female students with low academic performance levels from EG1 and EG2 was 3-4 times less than in CG ( $p \leq 0.01)$, while with average - 1.2-1.3 times more ( $p \leq 0.05)$. As for high educational outcomes, these differences constituted 1.5 times in favour of EG1 and EG2 ( $p \leq 0.05)$.

\section{Figure 4 - Changes in performance of female respondents}

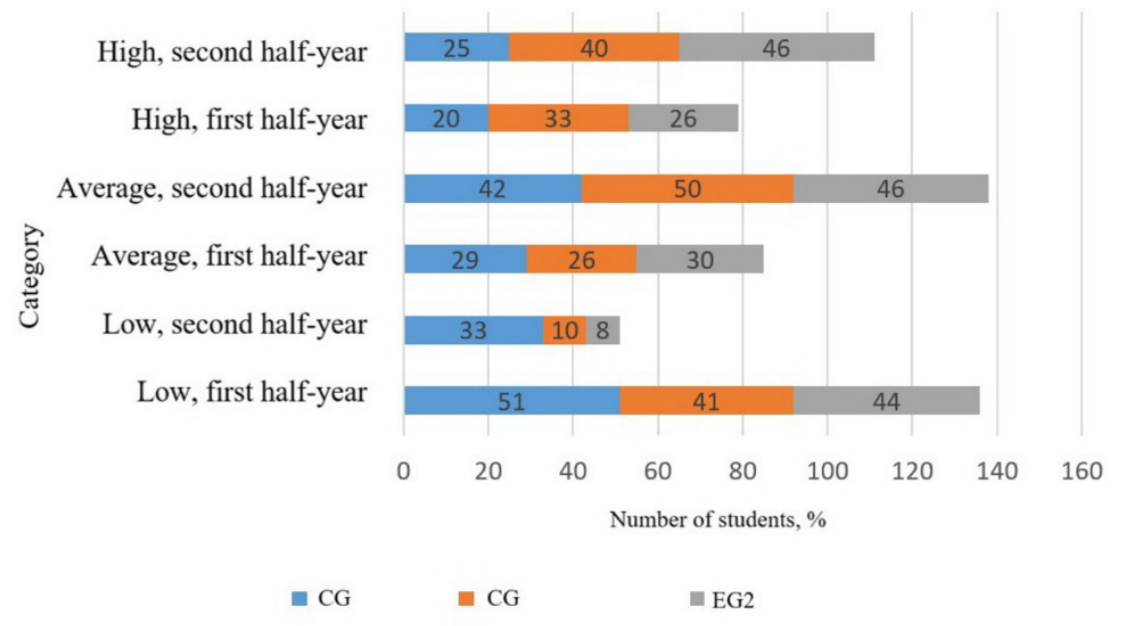

Source: Own development

Thus, no significant difference between the academic performance of males and females was revealed. However, in view of the fact that EG2 students underwent individual training with teachers in face-to-face mode, they generally showed 1.1-1.2 times better results compared to their fellows from EG1 involved in group training. 
Sensibility and Rationality in Vocal Music: The Issue of Intonation Di Wang

\section{Discussion}

The conducted experiment showed that the greatest negative changes in terms of health occurred in CG. The use of traditional training methodology without intonational self-control on the part of the student caused an increasing number of dropouts due to socalled occupational diseases (disorders in the work of respondents' vocal apparatuses). Therefore, it is necessary to observe strict measures for monitoring students' health. The study also demonstrated an increase in the incidence among CG participants with practically zero disease rates in both EGs. This proves the value of the developed methodology, which implies monitoring intonation when singing and, thus, maintains the health and normal functioning of vocal apparatus. The examination performed unveiled that the considered teaching technique positively influenced the overall respondents' performance. The most notable changes were observed for students with poor academic results. After the experiment end, their achievements improved greatly, and most of such individuals in EGs moved to subgroups with moderate and high-performance indicators. Consequently, one can draw the conclusion that students' academic success can be enhanced by providing more diversified and properly organized training.

Students from EGs purposefully and constantly worked on their intonation to improve it. They were also involved in concerts in a real opera studio. Given that EG2 participants had the opportunity to work with teachers individually, they had somewhat better training outcomes than students from EG1.

As during the other examinations, the current study identified that individuals majoring in vocal music tend to prioritize the availability of musical talent and knowledge of theory (POORNA et al., 2015; ZWAN, 2006). In the meantime, it was noted that in the second half of the year, there was a change in priorities, i.e., students considered self-criticism and self-control to be one of the most important personal qualities leading to success. 
Sensibility and Rationality in Vocal Music: The Issue of Intonation Di Wang

A well-known fact is that one must be able to control his/her breathing in the right way to become a good singer. Literature sources covering the fundamentals of vocal pedagogy identify voluntary and involuntary exhalation types (AMIR et al., 2006). The first is based on reflexes; in other words, has uncontrolled nature. During voluntary exhalation, the air flows out of the lungs, and the sound fades away. Accordingly, the pitch also decreases. The involuntary exhalation is controlled bythesinger's brain and requires large air volumes. The basis for singing intonation is the so-called primary tone, which means the note that sounds best in the middle of the sounding range. If there are several such tones, then they form a primary area (PÓŁROLNICZAK and ŁAZORYSZCZAK, 2011). While preparing to performance, the starting point for a singer is the prediction of the primary tone or clear understanding of its position. In the process of singing, a person, first of all, practices in controlling intonations (LIVINGSTONE and RUSSO, 2018). Further, as the talent develops, the range of necessary abilities expands. Thus, after the improvement of breathing and achieving deeper emotional immersion, the future singer is to be able to transfer the sensations of the primary tone to subsequent tones (MUHAMMAD and MELHEM, 2014). Using the novel technique of intonation control allowed students to strengthen their professional qualities. Nevertheless, the issue under consideration requires a more thorough examination. The future work in this field will be focused on investigating the hidden advantages of private classes over group ones.

\section{Conclusions}

As a result of the conducted experiment, an inverse relationship was established between the students' control of intonation and the overall health of their vocal apparatuses. In $\mathrm{CG}$, the correlation coefficient equaled -0.89 , in EG1 - 0.78, and in EG2 - 0.81. The proposed methodology allowed respondents 
Sensibility and Rationality in Vocal Music: The Issue of Intonation Di Wang

from EGs to preserve the good health of their vocal cords. In terms of academic performance, no significant difference between male and female research participants was noticed. However, those students who studied individually (EG2) showed 1.1-1.2 times better results compared to those from EG1 involved in group training. The opportunity to participate in concerts and opera performances very positively impacted EG's performance. Working in a team environment also influenced qualitative characteristics of students' singing; though, the most crucial factor determining the success of EGs was intonation control. Only due to the systematic and constant work, the number of students with poor academic performance decreased with subsequent noticeable increase in the number of those with average and high educational achievements.

\section{References}

AMIR, Noam, MICHAELI, Orit, AMIR, Ofer. Acoustic and perceptual assessment of vibrato quality of singing students. Biomedical Signal Processing and Control, v. 1, n. 2, p. 144-150, 2006.

BERTERO, Dario, FUNG, Pascale. A first look into a convolutional neural network for speech emotion detection. 2017 IEEE International Conference on Acoustics, Speech and Signal Processing (ICASSP), p. 5115-5119, 2017.

D'AMARIO, Sara, DAFFERN, Helena. Using electrolaryngography and electroglottography to assess the singing voice: A systematic review. Psychomusicology: Music, Mind, and Brain, v. 27, n 4, p. 229-243, 2017.

D'AMARIO, Sara, HOWARD, David M., DAFFERN, Helena, PENNILL, Nicola. A Longitudinal Study of Intonation in an a cappella Singing Quintet. Journal of Voice, v. 34, n. 1, p. 159-159, 2020.

D'AMARIO, SARA, DAFFERN, Helena, BAILES, Freya. Synchronization in singing duo performances: The roles of visual contact and leadership instruction. Frontiers in Psychology, v. 9, p. 1208, 2018. 
Sensibility and Rationality in Vocal Music: The Issue of Intonation Di Wang

D'AMARIO, Sara, DAFFERN, Helena, BAILES, Freya. A new method of onset and offset detection in ensemble singing. Logopedics Phoniatrics Vocology, v. 44, n. 4, p. 143-158, 2019.

D'AMARIO, Sara, DAFFERN, Helena, BAILES, Freya. A longitudinal study investigating synchronization in a singing quintet. Journal of Voice, $v$. 34, n. 1, p. 159, 2020.

DAFFERN, Helena. Blend in singing ensemble performance: Vibrato production in a vocal quartet. Journal of Voice, v. 31, n. 3, p. 385, 2017. DELIĆ, Vlado, PERIĆ, Zoran, SEČUJSKI, Milan, JAKOVLJEVIĆ, Nikša, NIKOLIĆ, Jelena, MIŠKOVIĆ, Dragiša, SIMIĆ, Nikola, SUZIĆ, Siniša, DELIĆ, Tijana. Speech technology progress based on new machine learning paradigm. Computational Intelligence and Neuroscience, n. 1, p. 4368036, 2019. DEVANEY, Johanna, MANDEL, Michael I., ELLIS, Daniel P., FUJINAGA, Ichiro. Automatically extracting performance data from recordings of trained singers. Psychomusicology: Music, Mind \& Brain, v. 21, p. 108-136, 2011. GINSBORG, Jane, KING, Elaine. Rehearsal talk: Familiarity and expertise in singer-pianist duos. Musicae Scientiae, v. 16, n. 2, p. 148-167, 2012. GONTARENKO, N. B. Solo singing: secrets of vocal skill. 2nd edition. Rostov on Don: Phoenix Publishing house, 2007. 314 p.

HAVRØY, Frank. 'You cannot just say: "I am singing the right note'. Discussing intonation issues with Neue Vocalsolisten Stuttgart. Music + Practice, v. 1, n. 1, p. 1-7, 2013.

HAVRØY, Frank. Alone Together. Vocal Ensemble Practice Seen through the Lens of Neue Vocalsolisten Stuttgart. Oslo: Norges musikkhøgskole, 2015. 158 p.

HOWARD, David M. Equal or non-equal temperament in a capella SATB singing. Logopedics phoniatrics vocology, v. 32, n. 2, p. 87-94, 2007.

HOWARD, David M., ANGUS, Jamie. Acoustics and psychoacoustics. Milton Park: Taylor \& Francis, 2017.

KERKENI, Leila, SERRESTOU, Youssef, RAOOF, Kosai, CLEDER, Catherine, MAHJOUB, Mohamed Ali, MBARKI, Mohamed. Automatic Speech Emotion Recognition Using Machine Learning. Social Media and Machine Learning, p. 1-16, 2019. 
Sensibility and Rationality in Vocal Music: The Issue of Intonation Di Wang

KUMAR, Mukesh, SHIMI S. L. Voice recognition based home automation system for paralyzed people. International Journal of Advanced Research in Electronics and Communication Engineering, v. 4, n. 10, p. 2508-2515, 2015.

LIVINGSTONE, Steven R., RUSSO, Frank A. The Ryerson Audio-Visual Database of Emotional Speech and Song (RAVDESS): A dynamic, multimodal set of facial and vocal expressions in North American English. Plos one, v. 13, n. 5, p. e0196391, 2018.

MARKOFF, John. From Your Mouth to Your Screen, Transcribing Takes the Next Step. The New York Times, 2019. Available at <https://www. nytimes.com/2019/10/02/technology/automatic-speech-transcriptionai.html>. Accessed 15 Jan 2020

MUHAMMAD, Ghulam, MELHEM, Moutasem. Pathological voice detection and binary classification using MPEG-7 audio features. Biomedical Signal Processing and Control, v. 11, p. 1-9, 2014. MUNIR, Alina, S. EHSAN, Kashif, MOHSIN, Raza, MUDASSIR, Mumajjed. Face and speech recognition based smart home. 2019 International Conference on Engineering and Emerging Technologies, p. 1-5, 2019. PÓŁROLNICZAK, Edward, Łazoryszczak, Miroslaw. Quality assessment of intonation of choir singers using $\mathrm{fO}$ and trend lines for singing sequence. Metody Informatyki Stosowanej, v. 4, p. 259-268, 2011.

POORNA, S. S., JEEVITHA, C.Y., NAIR, S. J., SANTHOSH, S., NAIR, G. J. Emotion recognition using multi-parameter speech feature classification. 2015 International Conference on Computers, Communications, and Systems (ICCCS), p. 217-222, 2015.

SCHERER, Klaus R., SUNDBERG, Johan, TAMARIT, Lycas, SALOMÃO, Gláucia L. Comparing the acoustic expression of emotion in the speaking and the singing voice. Computer Speech \& Language, v. 29, n. 1, p. 218-235, 2015.

SEZGIN, Mehmet Cenk, GUNSEL, Bilge, KURT, Gunes Karabulut. Perceptual audio features for emotion detection. EURASIP Journal on Audio, Speech, and Music Processing, v. 1, p. 16, 2012. 
Sensibility and Rationality in Vocal Music: The Issue of Intonation Di Wang

ZAPOROWSKI, Szymon, CZYŻEWSKI, Andrzej. Selection of features for multimodal vocalic segments classification. In: International Conference on Multimedia and Network Information System. Cham: Springer, 2019. p. 490-500.

ZAPOROWSKI, Szymon, KOSTEK, Bozena. Ranking Speech Features for Their Usage in Singing Emotion Classification. In: HELIC, Denis, LEITNER, Gerhard, STETTINGER, Martin, FELFERNIG, Alexandr, RAŚ, Zbigniew (Eds.), Foundations of Intelligent Systems. ISMIS 2020. Lecture Notes in Computer Science. Cham: Springer, 2020. vol. 12117, p. 225234.

ZHANG, Xiao-Ying, SONG, Yi-Chuan, LIU, Chang-Bin, QIN, Chuan, LIU, Song-Huai, LI, Jian-Jun. Effectiveness of oral motor respiratory exercise and vocal intonation therapy on respiratory function and vocal quality in patients with spinal cord injury: a randomized controlled trial. Neural regeneration Research, v. 16, n. 2, p. 375-381, 2020.

ZHAO, Jianfeng, MAO, Xia, CHEN, Lijiang. Speech emotion recognition using deep 1D \& 2D CNN LSTM networks. Biomedical Signal Processing and Control, v. 47, p. 312-323, 2019.

ZWAN, Pawel. Expert system for automatic classification and quality assessment of singing voices. In: Audio Engineering Society

Convention 121. New York: Audio Engineering Society, 2006. vol. 1, 446-454.

\section{Publisher}

Federal University of Goiás. School of Music and Performing Arts. Graduate Program in Music. Publication in the Portal of Periodicals UFG.

The ideas expressed in this article are the responsibility of their authors, and do not necessarily represent the opinion of the editors or the university. 